\title{
ELECTROCHEMICAL CHARACTERIZATION OF AZ31 MAGNESIUM ALLOY TREATED BY ULTRASONIC IMPACT PEENING (UIP)
}

\begin{abstract}
Electrochemical characteristics of AZ31 magnesium alloy after impacting by ultrasonic impact peening (UIP) were measured in order to evaluate its effect on corrosion resistance of mentioned alloy. For this purpose, potentio-dynamic polarization (PD) tests and electrochemical impedance spectroscopy (EIS) of ground and impacted samples were performed in $0.1 \mathrm{M} \mathrm{NaCl}$ solution at the temperature of $22 \pm 2{ }^{\circ} \mathrm{C}$ after 5 minutes of potential stabilization. The obtained PD curves were analysed using the Tafel extrapolation method and data from EIS measurements in form of Nyquist plots were quantified by the equivalent circuit method. The results showed clearly that application of the UIP significantly deteriorated corrosion resistance of AZ31 alloy in the chosen testing solution.
\end{abstract}

Keywords: magnesium alloy, corrosion, ultrasonic impact peening

\section{Introduction}

Despite of all the well-known convenient properties of magnesium and its alloys, such as low weight, highest specific strength of all metal materials, good damping capacity etc., their applications are still not widely spread due to the insufficient corrosion performance [1], [2], [3], [4], [5]. Generally it is proposed that this derogation is caused by synergic effect of negative standard potential value ( $-2.36 \mathrm{~V}$ vs. SHE), impurities $(\mathrm{Fe}, \mathrm{Ni}, \mathrm{Cu}, \ldots)$, which leads to a micro galvanic effect and non-protective quasi-passive film based on magnesium oxide or hydroxide depending on the nature of environment [6], [7], [8]. This surface film is stable only in highly alkaline solutions [9], [10]. Magnesium and its alloys exhibit strange behaviour during the anodic polarisation called the negative difference effect (or according to the latest researches it is better to call it "anomalous hydrogen evolution"), which is represented by the hydrogen evolution (HE) during the anodic reaction [11], [12], [13]. Normally, hydrogen evolution is an accompanying feature of cathodic reaction during the corrosion of metals so there is an intense effort to explain this strange behaviour [14], [15], [16]. Nowadays, researches are focused on increasing of corrosion resistance of $\mathrm{Mg}$ alloys by preparation of resistant barrier e.g. coatings, plating or by modification of surface characteristics [17], [18], [19]. Recent works, aimed at application of ultrasonic impact peeing (UIP), propose that this technique has a positive effect on mechanical properties of various materials (steels, Co and $\mathrm{Ti}$ alloys and welded materials, etc.), increase the fatigue characteristics and also enhance their corrosion resistance. Due to those pros, the UIP has become a common technology in automotive and civil engineering. Its main principle is represented by deformation of surface by impacts with ultrasonic frequency, which induce favourable compressive residual stresses and decrease harmful tensile stresses in a surface layer. The more detailed description of this method could be found elsewhere [20], [21], [22], [23], [24].

To our best knowledge, the extensive research on influence of the UIP application on corrosion properties (and also on mechanical properties) of magnesium alloys has not been done yet. Therefore, the aim of this contribution is to compare electrochemical characteristics of AZ31 magnesium alloy before and after the UIP by means of potentio-dynamic polarization tests and electrochemical impedance spectroscopy in sodium chloride solution and thus evaluate its effect on corrosion resistance of this alloy.

\section{Experimental material and methods}

The AZ31 magnesium alloy has been prepared by continual casting and subsequently heat treated by homogenizing at temperature of $420{ }^{\circ} \mathrm{C}$ for 16 hours. Chemical composition of AZ31 Mg alloy (Table 1) has been obtained by the EDXRF analysis on ARL QUANT'X EDXRF Spectrometer. In order to evaluate the microstructure of the material, samples have been ground by an emery paper $\mathrm{p} 1000$, then polished by polishing discs MD Dac and MD Chem using proper polishing emulsions on Struers Tegramin-30 machine. Samples have been etched for 10 seconds by etchant composed of picric acid, acetic acid, ethanol and water [18], [25]. The microstructure has been observed using the ZEISS Axio Imager.Z1M light optical microscope.

The ultrasonic impact peening (UIP) has been performed using the CNC mill with mounted ultrasonic impact head (see Figure 1), equipped with a cooling system, which kept the constant temperature during impacting. The samples have been ground by an emery paper p1000 to obtain the uniform surface

\footnotetext{
* 1,2Daniel Kajanek, ${ }^{2}$ Branislav Hadzima, ${ }^{2}$ Filip Pastorek

${ }^{1}$ Department of Materials Engineering, Faculty of Mechanical Engineering, University of Zilina, Slovakia

${ }^{2}$ Research Centre, University of Zilina, Slovakia

E-mail: daniel.kajanek@fstroj.uniza.sk
} 
Table 1 Chemical composition of AZ31 magnesium alloy

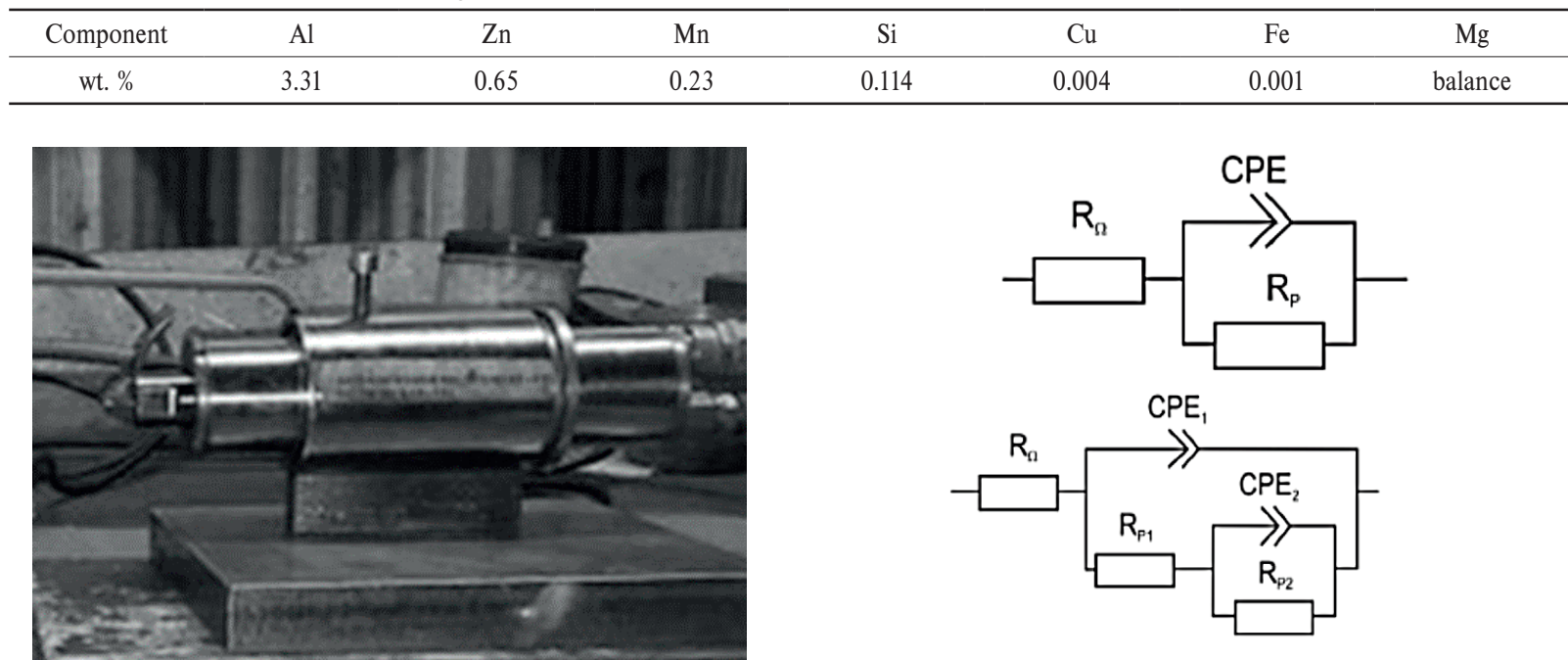

Figure 1 Ultrasonic impact head

roughness before application of the UIP. The parameters of the UIP process have been set as follows: pressure force of $85 \mathrm{~N}$, ultrasonic frequency of $20 \mathrm{kHz}$ and the treatment time has been 5 minutes.

To observe influence of the UIP on surface of AZ31, photo documentation of ground and the UIP treated samples have been created by the stereomicroscope OLYMPUS SZX16 and supported by documentation of the cross-section view made by the ZEISS Axio Imager.Z1M light microscope with corresponding software.

With the aim to evaluate the corrosion resistance, electrochemical characteristics of ground samples and samples treated by the UIP have been measured by electrochemical impedance spectroscopy (EIS) and potentio-dynamic polarization (PD) tests. All of the experiments have been carried out in $0.1 \mathrm{M}$ $\mathrm{NaCl}[26]$ at the temperature of $22 \pm 2{ }^{\circ} \mathrm{C}$ on potentiostat VSP Biologic SAS, using the three electrode cell system with following configuration: AZ31 - working electrode, Pt electrode - counter electrode, saturated calomel electrode - reference electrode $(+0.2446 \mathrm{~V}$ vs. SHE). The stabilization of potential between the working electrode and electrolyte has been set on 5 minutes for both EIS measurements and PD tests. The software EC Lab V10.34 has been used for analysis of data obtained by all the mentioned electrochemical techniques.

During the EIS measurements, amplitude of applied voltage has been set to $15 \mathrm{mV}$ and the frequency ranged from $100 \mathrm{kHz}$ to $10 \mathrm{mHz}$ with change of 10 points per decade. The average value of voltage has been set on open circuit potential value [27]. The measured curves have been plotted in the shape of Nyquist diagrams. Those diagrams have been quantitatively described by the equivalent circuit method. The equivalent circuits used for the analysis are shown in Figure 2. Circuit represented in Figure 2 (left) has been used for the Nyquist plots with one capacitance loop and describes situation with homogenous conditions on the surface. Figure 2 (right) shows the equivalent circuit used for analysis of Nyquist diagram with two capacitance loops and interprets occurrence of locations with different electrochemical behaviour. For the correct interpretation of the Nyquist diagrams
Figure 2 Equivalent circuits for diagrams with one capacitance loop (up) and two capacitance loops (down)

it is important to know the meaning of the circuit components. Solution resistance is represented by the $R_{\Omega}$ component and the CPE is a constant phase element, which replaces capacitor in the circuit and describes the heterogeneity of electrode's surface. The component $\mathrm{R}_{\mathrm{p}}$ is called the polarization resistance of sample/electrolyte interface. If the Nyquist plot is composed of two capacitance loops, final polarization resistance will be given by the sum of partial polarization resistances $R_{p 1}$ and $R_{p 2}$ [28]. Their interpretation depends on the particular system and will be explained in the discussion part.

Potential, ranged from $-200 \mathrm{mV}$ to $+500 \mathrm{mV}$, has been applied on the AZ31 samples with the rate of $1 \mathrm{mV} \cdot \mathrm{s}^{-1}$ during the PD tests. The range of potentials have been set with respect to open circuit potential [18]. The measured data of PD tests are represented by potentiodynamic polarization curves which have been analysed by the Tafel extrapolation method in order to obtain electrochemical characteristics e.g. corrosion potential $\mathrm{E}_{\text {corr }}$, corrosion current density $\mathrm{i}_{\text {corr }}$ and calculated corrosion rate $\mathrm{r}_{\text {corr }}$.

\section{Results and discussion}

The AZ31 alloy's microstructure (Figure 3) consists of polyhedral grains of solid solution of aluminium, zinc and other alloying elements in magnesium. Intermetallic phase $\mathrm{Mg}_{17} \mathrm{Al}_{12}$ is localised along the grain boundaries. There are also areas of twins caused by the deformation during the cutting and preparation of samples.

The difference between the ground surface and surface after the impact treatment can be observed from the documentation shown in Figure 4. Application of ultrasonic impacts has caused deformation of the surface and subsequently increased reactivity, which has led to the accelerated formation of film on the sample's surface. According to nature of the UIP process and surrounding environment, it can be assumed that the main constituent of the film is $\mathrm{MgO}$ with small amount of $\mathrm{Mg}(\mathrm{OH})_{2}$ as the environment has certain amount of moisture [9], [10]. It has to be kept in mind that constituents from the cooling system could be present, 


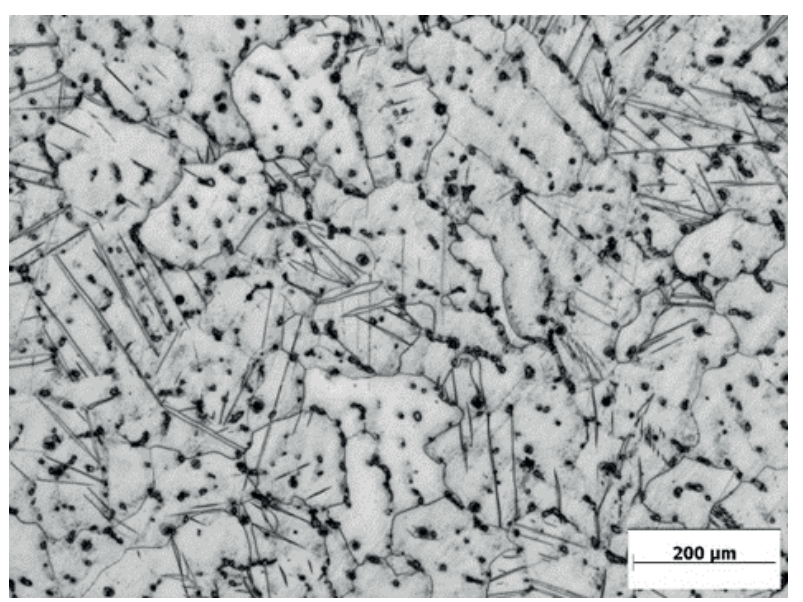

Figure 3 Microstructure of $\mathrm{AZ} 31 \mathrm{Mg}$ alloy
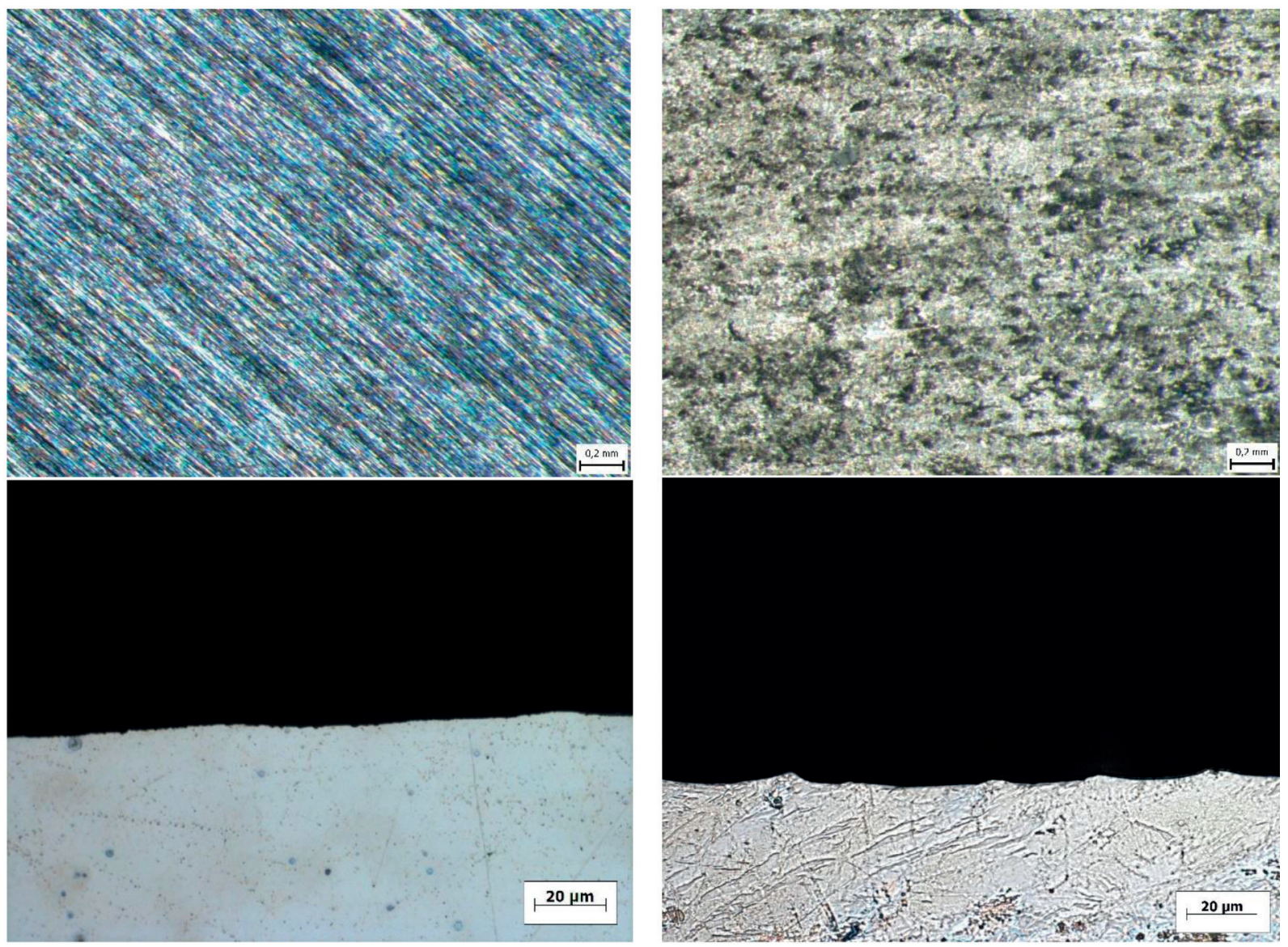

Figure 4 Surfaces of ground (upper left) and UIP influenced samples (upper right) with cross sectional view of ground (left bottom) and UIP surface (right bottom)

as well. According to literature, the thickness of such a film is in nanoscale range and thus it is difficult to observe it by the light microscopy [29]. The exact chemical composition of the film is going to be examined by XPS analysis in further research studies. As can be seen from the UIP influenced surface and from the cross- sectional views, several defects and holes are introduced to the surface. This kind of defects increases electrochemically active area, which is in contact with environment and could negatively affect corrosion performance of $\mathrm{Mg}$ parts [30].

The Nyquist diagrams as results of the EIS measurements in $0.1 \mathrm{M} \mathrm{NaCl}$, for ground samples and the UIP influenced samples, are displayed in Figure 5. Values of electrochemical characteristics obtained by equivalent circuit analysis are listed in Table 2. As can be seen, diagram of ground samples consists of two capacitance loops and diagram of the UIP samples is created by one capacitance loop, which pointed to different electrochemical behaviour. In the case of ground samples, high capacitance loop represented by value of $\mathrm{R}_{\mathrm{p} 1}$ describes resistance of the corrosion product barrier $\left(\mathrm{Mg}(\mathrm{OH})_{2}\right.$ and $\mathrm{MgCl}_{2}$ considering testing electrolyte) created on the surface while exposed to the solution. The low capacitance loop represented by value $\mathrm{R}_{\mathrm{p} 2}$, is analysed as charge transfer resistance of the surface/electrolyte 
Table 2 Electrochemical characteristics obtained by EIS measurements in $0.1 \mathrm{M} \mathrm{NaCl}$

\begin{tabular}{cccc}
\hline & $\mathrm{R}_{\Omega}$ & $\mathrm{R}_{\mathrm{p} 1}$ & $\mathrm{R}_{\mathrm{p} 2}$ \\
$\left(\Omega \cdot \mathrm{cm}^{2}\right)$ & $\left(\Omega \cdot \mathrm{cm}^{2}\right)$ & $919 \pm 14$ & $\mathrm{R}_{\mathrm{p}}$ \\
$\left(\Omega \cdot \mathrm{cm}^{2}\right)$ & $1270 \pm 23$ & - & $2189 \pm 37$ \\
Ground AZ31 & $124 \pm 6$ & $68 \pm 7$ & $68 \pm 7$ \\
\hline
\end{tabular}

Table 3 Electrochemical characteristics obtained by PD tests of in $0.1 \mathrm{M} \mathrm{NaCl}$

\begin{tabular}{cccccc}
\hline & $\begin{array}{c}\mathrm{E}_{\text {corr }} \\
(\mathrm{mV})\end{array}$ & $\begin{array}{c}\mathrm{i}_{\text {corr }} \\
\left(\mu \mathrm{A} / \mathrm{cm}^{2}\right)\end{array}$ & $\begin{array}{c}\boldsymbol{\beta}_{\mathrm{a}} \\
(\mathrm{mV} / \mathrm{dec} .)\end{array}$ & $\begin{array}{c}\boldsymbol{\beta}_{\mathrm{c}} \\
(\mathrm{mV} / \mathrm{dec} .)\end{array}$ & $\begin{array}{c}\mathrm{r}_{\text {corr }} \\
(\mathrm{mm} / \mathrm{year})\end{array}$ \\
\hline Ground AZ31 & $-1508 \pm 20$ & $18 \pm 1.1$ & $76 \pm 6$ & $131 \pm 9$ & $0.8 \pm 0.03$ \\
UIP AZ31 & $-1433 \pm 17$ & $98 \pm 6.4$ & $193 \pm 11$ & $205 \pm 21$ & $4.5 \pm 0.7$ \\
\hline
\end{tabular}

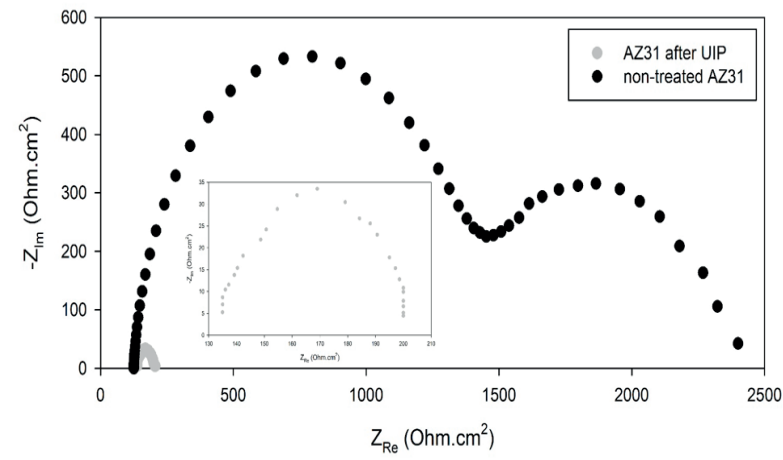

Figure 5 Nyquist plots of ground and UIP influenced samples measured in $0.1 \mathrm{M} \mathrm{NaCl}$

interface. Diagram of UIP samples consist of one capacitance loop. It indicates homogenous conditions on the surface during the exposition. The polarization resistance of these samples is represented by charge transfer resistance of sample/electrolyte interface. According to shape of diagrams for both states it can mentioned that degradation mechanism is under charge transfer control [31]. Final values of polarization resistance $R_{p}$ shown in Table 2 point to significant difference between the ground and UIP samples. The ground samples have reached the polarization resistance value of $2189 \Omega . \mathrm{cm}^{2}$ and UIP samples have reached $R_{p}$ of $68 \Omega . \mathrm{cm}^{2}$ which is difference of more than 32-times. It means that application of UIP on AZ31 has led to significant reduction of corrosion resistance as the polarization resistance is in direct relation with corrosion performance.

The PD tests have been performed in $0.1 \mathrm{M} \mathrm{NaCl}$ to obtain information about corrosion thermodynamics (corrosion potential $\mathrm{E}_{\text {corr }}$ ) and kinetics (corrosion current density $\mathrm{i}_{\text {corr }}$ ) of samples. Potentiodynamic polarization curves of ground and UIP samples are shown in Figure 6 and corresponding values of electrochemical characteristics are stated in Table 3. The UIP samples have reached the $\mathrm{E}_{\text {corr }}$ value of $-1433 \mathrm{mV}$. This value is more positive compared to value of ground samples $(-1508 \mathrm{mV})$. Despite small potential difference, results point to slightly higher thermodynamic nobility of UIP samples compared to ground samples. In terms of corrosion kinetics, the UIP samples have reached more than 5-times higher value of corrosion current density $\left(98 \mu \mathrm{A} / \mathbf{c m}^{2}\right)$ in comparison to value reached by ground samples $\left(18 \mu \mathrm{A} / \mathbf{c m}^{2}\right)$. Current density is in direct proportionality

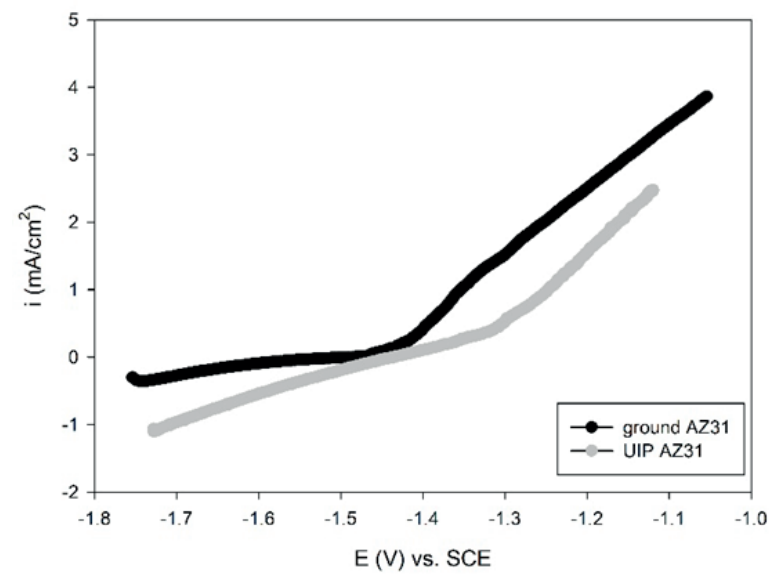

Figure 6 Potentiodynamic polarization curves of ground and UIP influenced samples measured in $0.1 \mathrm{M} \mathrm{NaCl}$

with corrosion rate and it means that also corrosion rate $r_{\text {corr }}$ is higher in case of UIP samples as it mentioned in Table 3. On the one hand UIP samples show better performance from thermodynamic point of view but on the other hand UIP samples are worse regarding corrosion kinetics. It has to be noted that corrosion of magnesium and its alloys is mainly driven by its kinetics hence the UIP has negatively influenced corrosion resistance of chosen alloy [10], [12]. These results are in good agreement with values obtained by EIS measurements.

It has to be bear in mind that there is possibly number of reasons which could influence corrosion process and their combination have led to worse corrosion resistance of UIP samples. According to the several authors, the film created on the surface (with composition mentioned above) provide a corrosion protection only in highly alkaline environment and thus is not able to protect $\mathrm{Mg}$ alloy for sufficient time in acidic and neutral solutions [9], [10], [29]. Furthermore, if $\mathrm{Cl}^{-}$ions are presented in solution, this film is broke down after short period and corrosion of underneath substrate takes place [12], [29]. The presence of quasi passive film can be also proved by shift of corrosion potential to more positive values. Another factor is that application of UIP leads to the creation of defects (enlarged active surface) and to inducing dislocation and vacations. The surface of samples became highly electrochemically active and thus formation of corrosion products barrier, which could slow down the degradation, becomes more complicated compared to ground samples which have reached better corrosion resistance [30], [31]. 


\section{Conclusion}

Based on the performed experiments, measurements and analysis of results, these conclusions can be stated:

- Application of ultrasonic impact peening led to the creation of surface film and defects on the surface of AZ31 magnesium alloy.

- Samples after UIP reached more than 32-times lower value of polarization resistance in $0.1 \mathrm{M} \mathrm{NaCl}\left(68 \Omega . \mathrm{cm}^{2}\right)$ compared to value of $R_{p}$ reached by ground samples $\left(2189 \Omega . \mathrm{cm}^{2}\right)$.

- UIP improved thermodynamic stability of AZ31 as the corrosion potential values of treated samples reached more positive $\mathrm{E}_{\text {corr }}(-1433 \mathrm{mV})$ compared to ground ones (-1508
$\mathrm{mV})$, although improvement is not significant. However corrosion kinetics became worse as the UIP samples reached more than 5-times higher value of corrosion current density $\mathrm{i}_{\text {corr }}\left(98 \boldsymbol{\mu} \mathbf{A} / \mathbf{c m}^{2}\right.$ vs. $\left.18 \boldsymbol{\mu} \mathbf{A} / \mathbf{c m}^{2}\right)$ and higher corrosion rate $\mathrm{r}_{\text {corr }}$ compared to the non-treated samples.

\section{Acknowledgement}

The research was supported by project ITMS 26220220048 and by Scientific Grant Agency of the Ministry of Education, Science, Research and Sport of the Slovak Republic under the contract VEGA no. 1/0045/17.

\section{References}

[1] MARUYAMA, K., SUZUKI, M., SATO, H.: Creep Strength of Magnesium-Based Alloys. Metallurgical and Materials Transactions A, 33, 875-882, 2002. https://doi.org/10.1007/s11661-002-0157-7

[2] MENG, X., WU, R., ZHANG, M., WU, L., CUI, CH.: Microstructures and Properties of Superlight Mg-Li-Al-Zn Wrought Alloys. Journal of Alloys and Compounds, 486, 722-725, 2009. https://doi.org/10.1016/j.jallcom.2009.07.047

[3] DARGUSCH, M. S., PETTERSEN, K., NOGITA, K., NAVE, M. D., DUNLOP, G. L.: The Effect of Aluminium Content on the Mechanical Properties and Microstructure of Die Cast Binary Magnesium-Aluminium Alloys. Materials Transactions, 47(4), $977-$ 982, 2006. https://doi.org/10.2320/matertrans.47.977

[4] JUN, C., QING, Z., QUAN-AN, L.I.: Effect of Y and Ca Addition on the Creep Behaviors of AZ61 Magnesium Alloys. Journal of Alloys and Compounds, 686, 375-383, 2016. https://doi.org/10.1016/j.jallcom.2016.06.015

[5] BUKOVINOVA, L., BUKOVINA, M., PASTOREK, F.: Influence of Microstructural Features on the Corrosion Behaviour of AZ91 Alloy in Chloride Media. Materials Engineering - Materialove inzinierstvo, 21, 153-158, 2014.

[6] ATRENS, A., SONG, G.-L., LIU, M., SHI, Z., CAO, F., DARGUSCH, M. S.: Review of Recent Developments in the Field of Magnesium Corrosion. Advanced Engineering Materials, 17(4), 400-453, 2015. https://doi.org/10.1002/adem.201400434

[7] FRIEDRICH, H. F., MORDIKE, B. L.: Magnesium Technology, $1^{\text {st }}$ edition. Springer, New York, 2006.

[8] ABBOT, T. B.: Magnesium: Industrial and Research Developments over the Last 15 years. Corrosion, 71(2), 120-127, 2015. https:// doi.org/10.5006/1474

[9] GUSIEVA, K., DAVIES, C. H. J., SCULlY, J. R., BIRBILIS, N.: Corrosion of Magnesium Alloys: The Role of Alloying. International Materials Reviews, 60, 169-194, 2014. https://doi.org/10.1179/1743280414Y.0000000046

[10] SONG, G. L.: Corrosion of Magnesium Alloys, 1st edition. Woodhead Publishing, Philadelphia, 2011.

[11] ATRENS, A., DIETZEL, W.: The Negative Difference Effect and Unipositive Mg. Advanced Engineering Materials, 9(4), 292-297, 2007. https://doi.org/10.1002/adem.200600275

[12] ESMAILY, M., SVENSSON, J. E., FAJARDO, S., BIRBILIS, N., FRANKEL, G.S., VIRTANEN, S., ARRABAL, R., THOMAS, S., JOHANSSON, L. G.: Fundamentals and Advances in Magnesium Alloy Corrosion. Progress in Materials Science, 89, 92-193, 2017. https://doi.org/10.1016/j.pmatsci.2017.04.011

[13] CZERWINSKI, F.: Magnesium Alloys-Corrosion and Surface Treatments, $1^{\text {st }}$ edititon. InTech, Rijeka, 2011.

[14] BIRBILIS, N., KING, A. D., SINU, T., FRANKEL, G., SCULLY, J. R.: Evidence for Enhanced Catalytic Activity of Magnesium Arising from Anodic Dissolution. Electrochimica Acta, 132, 277-283, 2014. https://doi.org/10.1016/j.electacta.2014.03.133

[15] LAMAKA, S. V., HOCHE, D., PETRAUSKAS, R. P., BLAWERT, C., ZHELUDKEVICH, M. L.: A New Concept for Corrosion Inhibition of Magnesium: Suppression of Iron Re-Deposition. Electrochemistry Communications, 62, 5-8, 2016. https://doi. org/10.1016/j.elecom.2015.10.023

[16] IZQUIERDO, J., FERNANDEZ PEREZ, B. M., FILOTAS, D., ORI, Z., KISS, A., MARTIN GOMEZ, R. T., NAGY, L., NAGY, G., SOUTO, R. M.: Imaging of Concentration Distributions and Hydrogen Evolution on Corroding Magnesium Exposed to Aqueous Environments Using Scanning Electrochemical Microscopy. Electroanalysis, 28, 1-14, 2016. https://doi.org/10.1002/ elan. 201600265

[17] APELFELD, A., KRIT, B., LUDIN, V., MOROZOVA, N., VLADIMIROV, B., WU, R. Z.: The Characterization of Plasma Electrolytic Oxidation Coatings on AZ41 Magnesium Alloy. Surface and Coatings Technology, 322, 127-133, 2017. https://doi. org/10.1016/j.surfcoat.2017.05.048

[18] KAJANEK, D., PASTOREK, F., FINTOVA, S., BACA, A.: Study of Corrosion Behavior of Dicalcium Phosphate-Dihydrate (DCPD) Coating Prepared by Large Amplitude Sinusoidal Voltammetry (LASV) Technique on ZW3 Magnesium Alloy. Proceedia Engineering, 192, 399-403, 2017. https://doi.org/10.1016/j.proeng.2017.06.069 
[19] OMASTA, M., HADZIMA, B., PASTOREK, F.: Study of Calcium Phosphate (OCP) Electrodeposition Process on Elektron 21 Magnesium Alloy Surface. Materials Science Forum, 818, 115-120, 2015. https://doi.org/10.4028/www.scientific.net/MSF.818.115

[20] MALAKI, M., DING, H.: A Review of Ultrasonic Peening Treatment. Materials and Design, 87, 1072-1086, 2015. https://doi. org/10.1016/j.matdes.2015.08.102

[21] DONG, Z., LIU, Z., LI, M., LUO, J. L., CHEN, W., ZHENG, W., GUZONAS, D.: Effect of Ultrasonic Impact Peening on the Corrosion of Ferritic-Martensitic Steels in Supercritical Water. Journal of Nuclear Materials, 457, 266-272, 2015.

[22] MORDYUK, B. N., PROKOPENKO, G. I.: Ultrasonic Impact Peening for the Surface Properties' Management. Journal of Sound and Vibration, 308, 855-866, 2007. https://doi.org/10.1016/j.jsv.2007.03.054

[23] RODOPOULOS, C. A., PANTELAKIS, S. G., PAPADOPULOS, M. P.: The Effect of Ultrasonic Impact Treatment on the Fatigue Resistance of Friction Stir Welded Panels. Journal of Materials Engineering and Performance, 18(9), 1248-1257, 2009. https://doi. org/10.1007/s11665-009-9385-y

[24] FENG, Y., HU, S., WANG, D., CUI, L.: Formation of Short Crack and its Effect on Fatigue Properties of Ultrasonic Peening Treatment S355 Steel. Materials and Design, 89, 507-515, 2016. https://doi.org/10.1016/j.matdes.2015.10.009

[25] VOORT, G. F. V.: ASM Handbook Vol. 9: Metallography and Microstructures. ASM International, New York, 2004.

[26] RAI, X. J., NISHIMURA, T.: Studies on Galvanic Corrosion of Iron-Magnesium Couple by Scanning Electrochemical Microscopy in $0.1 \mathrm{M} \mathrm{NaCl}$ Solution. Journal of Industrial and Engineering Chemistry, 41, 141-150, 2016. https://doi.org/10.1016/j. jiec.2016.07.020

[27] KAJANEK, D., HADZIMA, B., PASTOREK, F., NESLUSAN JACKOVA, M.: Electrochemical Impedance Spectroscopy Characterization of ZW3 Magnesium Alloy Coated by DCPD Using LASV Deposition Technique. Acta Metallurgica Slovaca, 23(2), 147-154, 2017. https://doi.org/10.12776/ams.v23i2.900

[28] AMIRUDIN A., THIERRY D.: Application of Electrochemical Impedance Spectroscopy to Study the Degradation of PolymerCoated Metals. Progress in Organic Coatings, 26(1), 1-28, 1996.

[29] GHALI, E.: Corrosion Resistance of Aluminium and Magnesium Alloys, $1^{\text {st }}$ edition. John Wiley \& Sons Inc., New Jersey, 2010. https://doi.org/10.1002/9780470531778

[30] MHAEDE, M., PASTOREK, F., HADZIMA, B.: Influence of Shot Peening on Corrosion Properties of Biocompatible Magnesium Alloy AZ31 Coated by Dicalcium Phosphate Dihydrate (DCPD). Materials Science and Engineering C, 39, 330-335, 2014. https:// doi.org/10.1016/j.msec.2014.03.023

[31] ZHOU, J., YANG, Y., FRANK, M.A., DETSCH, R., BOCCACCINI, A.R., VIRTANEN, S.: Accelerated Degradation Behavior and Cytocompatibility of Pure Iron Treated with Sandblasting. Applied Materials and Interfaces, 8, 26482-26492, 2016. https:// doi.org/10.1021/acsami.6b07068 